
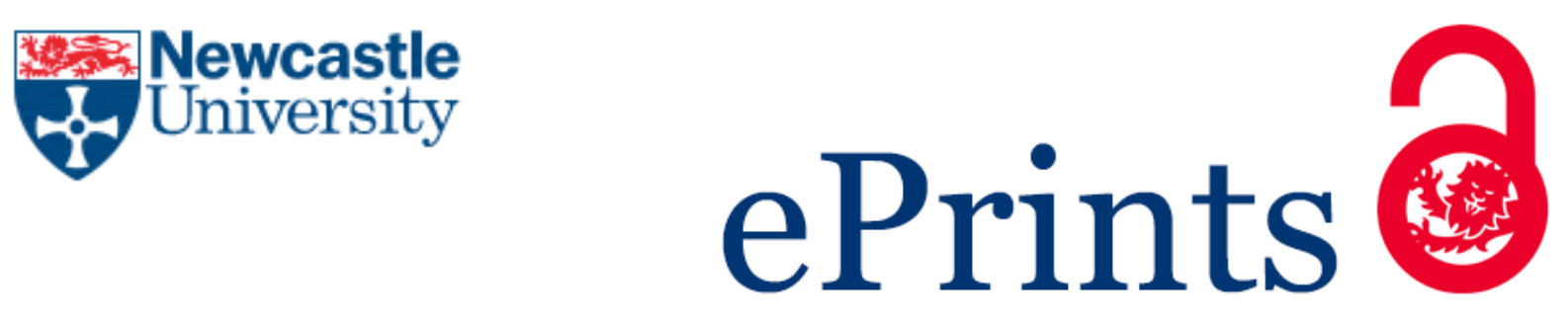

Comber H, Sharp L, de Camargo Cancela M, Haase T, Johnson H, Pratschke J.

Causes and outcomes of emergency presentation of rectal cancer. International Journal of Cancer 2016, 139(5), 1031-1039.

\title{
Copyright:
}

This is the peer reviewed version of the following article, which has been published in final form at http://dx.doi.org/10.1002/ijc.30149. This article may be used for non-commercial purposes in accordance with Wiley Terms and Conditions for Self-Archiving.

Date deposited:

$29 / 06 / 2016$

Embargo release date:

05 May 2017 


\section{Causes and outcomes of emergency presentation of rectal cancer}

HarryComber ${ }^{1}$

Linda Sharp ${ }^{2}$

Marianna de Camargo Cancela ${ }^{3}$

Trutz Haase ${ }^{4}$

Howard Johnson ${ }^{5}$

Jonathan Pratschke ${ }^{6}$

1. National Cancer Registry, Ireland

2. Institute of Health \& Society, Newcastle University, United Kingdom

3. Brazilian National Cancer Institute, Division of Population Research, Rio de Janeiro, Brazil

4. Social and Economic Consultant, Dublin, Ireland

5. Health \& Wellbeing Directorate Health Intelligence Unit, Health Service Executive, Ireland

6. Department of Economics and Statistics, University of Salerno, Italy

\section{Corresponding author}

Dr Harry Comber

Interim Director

National Cancer Registry

Building 6800

Cork Airport Business Park

Kinsale Road

Cork

T12 CDF7

Ireland

Telephone +353214318014

Email: h.comber@ncri.ie

This work was partly supported by grant HIC12COM from the Irish Cancer Society

\section{Novelty and impact statement}

We have distinguished various causes and effects of emergency presentation of rectal cancer, using a novel application of structural equation models to survival modelling. Living in an affluent area, private patient status and being married reduced hazard indirectly, by reducing emergency presentation. Emergency presentation was less likely to result in optimal 
treatment or admission to a high caseload hospital. Patient education and earlier access to endoscopic investigation for public patients could reduce emergency presentation. 


\section{Summary}

Emergency presentation of rectal cancer carries a relatively poor prognosis, but the roles and interactions of causative factors remain unclear. We describe an innovative statistical approach which distinguishes between direct and indirect effects of a number of contextual, patient and tumour factors on emergency presentation and outcome of rectal cancer. All patients diagnosed with rectal cancer in Ireland 2004-2008 were included. Registry information, linked to hospital discharge data, provided data on patient demographics, comorbidity and health insurance; population density and deprivation of area of residence; tumour type, site, grade and stage; treatment type and optimality; and emergency presentation and hospital caseload. Data were modelled using a structural equation model with a discretetime survival outcome, allowing us to estimate direct and mediated effects of the above factors on hazard, and their inter-relationships.

2,750 patients were included in the analysis. $12 \%$ had emergency presentations, which increased hazard by $80 \%$. Affluence, private patient status and being married reduced hazard indirectly by reducing emergency presentation. Older patients had more emergency presentations, while married patients, private patients or those living in less deprived areas had fewer than expected. Patients presenting as an emergency were less likely to receive optimal treatment or to have this in a high caseload hospital. Apart from stage, emergency admission was the strongest determinant of poor survival. The factors contributing to emergency admission in this study are similar to those associated with diagnostic delay. The socio-economic gradient found suggests that patient education and earlier access to endoscopic investigation for public patients could reduce emergency presentation.

Key words: rectal, emergency, survival, deprivation, insurance 


\section{Introduction}

Rectal cancer commonly presents as an emergency, and in up to $15 \%$ of cases the first presentation is unplanned ${ }^{1}$. Patients presenting as an emergency tend to have poorer survival 1-4. Emergency presentation may have been preceded by bowel obstruction, vomiting, haemorrhage or other co-morbidity, contributing to poorer post-operative survival. However the survival deficit persists for up to one year post-operatively ${ }^{4}$, in part due to the more advanced stage of the disease. Patients who present as an emergency are also more likely to be older, poorer, unmarried and to have more co-morbid conditions ${ }^{2,4}$ and to present to nonspecialist centres.

Most quantitative investigations of the factors leading to emergency presentation and delay in diagnosis have used Cox proportional hazards models, in which the relationship between prognostic factors is dealt with by adjustment, obscuring the role of mediating factors. This approach does not permit measurement of the extent to which any factor exerts a direct influence on the hazard, or an indirect one, mediated by one or more other factors.

Our primary objective was to assess the impact of socio-economic inequalities - in particular age, deprivation, marital status and possession of private health insurance- on survival from rectal cancer, and the role of emergency presentation in the observed variation in outcomes. Inequality in outcome is an important topic in itself, but variations between different groups can shed further light on the overall determinants of survival from rectal cancer. 


\section{Methods}

All cases of carcinoma of rectal/rectosigmoid cancer (ICD 10 sites C19 and C20) registered by the Irish National Cancer Registry (NCR) as incident during 2004-2008 were included in this study. The Registry has registered all incident cancers in the population of Ireland since 1994; completeness of registration of colon cancers has been estimated to be at least $97-98 \%$

${ }^{5}$. Patients who received no active tumour-directed treatment, defined as any resection, surgery (excluding bypass, reconstructive and cosmetic procedures), chemotherapy or radiotherapy with a primary aim of removing or reducing the tumour in the year following diagnosis, were excluded from analysis.

Information on patient age, sex and marital status, tumour stage, grade and treatment was obtained from NCR data. A Haase Pratschke affluence/deprivation score ${ }^{6}$ was assigned to each case, based on the area of residence of the patient at the time of diagnosis. Population density of the area of residence was obtained from the 2006 census of population ${ }^{7}$ and divided into approximate population tertiles of $<1,1-14.99$ and $\geq 15$ person per ha.

Treatment optimality was determined by comparison with the stage-specific recommendations of the National Comprehensive Cancer Network (NCCN) version $4.2013^{8}$ and classified as sub-optimal (less intensive treatment, or fewer modalities, than recommended by NCCN guidelines) or optimal/more aggressive (treatment according to the guidelines or using additional modalities).

Hospital of main treatment was determined for each patient from NCR data. In most cases the main hospital was that in which the patient had their major surgical procedure. For patients not having surgery $(17 \%)$ the main hospital was defined as that of radiotherapy, of chemotherapy or other tumour-directed treatment. Caseload for the main hospital was 
calculated as the annual average number of rectal cancer patients admitted during the study period, whether or not they received active treatment. Hospitals were classified as "low caseload" if 100 or fewer rectal cancer patients were admitted annually, and as "high caseload" otherwise.

Information on admission type (planned or emergency), co-morbidity and public/private patient status was added by linkage to the hospital in-patient episode (HIPE) database, which was available for all patients admitted to public hospitals. For patients who had no admissions to public hospitals $(222,6.5 \%)$, this information was coded as "planned", the modal value. Co-morbidity was calculated using the Charlson score, excluding the rectal cancer from the calculation. For $462(15 \%)$ of patients no information was available on comorbidity; these were treated as having the modal value of 0 . Information on health insurance was inferred from whether or not patients were treated privately. Uninsured patients in Ireland bear the full cost of private care in both public and private hospitals and rarely opt for this, while insured patients normally opt for private care. We therefore assumed that patients treated privately in public hospitals, as indicated in HIPE, and all those treated in private hospitals, had private health insurance.

Survival was calculated by linkage to death certificates provided by the Central Statistics Office, which gave date and cause of death. All patients not confirmed by this linkage to be dead were considered alive on the censoring date of 31/12/2011. Survival was modelled using a discrete-time survival model, which allows a survival outcome to be included within an arbitrarily complex Structural Equation Model ${ }^{9,10}$. The discrete-time survival model is very valuable for the present analysis, as it allows us to treat the influence of patient characteristics as being potentially mediated by emergency admission, caseload, stage of disease and treatment optimality, with treatment also depending on the aforementioned variables. In order to test these mediated effects, it is necessary to estimate a Structural Equation Model with a 
discrete-time survival outcome, a complex statistical model which can now be estimated using commercially-available software. This novel approach has the potential to shed light on an important and policy-relevant set of research questions regarding pathways of influence and mediation effects.

Figure 1 shows the model structure and all variables available for analysis, which were grouped into background variables-patient characteristics, tumour characteristics, contextual measures and year of diagnosis - and process of care variables — stage of disease, type of admission, treatment optimality and hospital caseload. The model examines the relationship of background characteristics (age, sex, deprivation, marital status, urban/rural residence, tumour site, grade and year of diagnosis) to stage at diagnosis, and the influence of background characteristics, as well as stage of disease, hospital caseload and planned/emergency presentation, on treatment optimality. Caseload, late stage, optimum treatment and planned/emergency presentation were also regressed on background characteristics. The model also allows all of the above variables to influence survival directly. In order to simplify the calculation and interpretation of the indirect effects, we report results for a model which specifies classical linear regression equations for all dependent variables, regardless of their measurement scale (with the exception of the dichotomous survival indicators). All models were estimated using version 5.21 of the software package MPlus ${ }^{10}$ using the MLR estimator. 


\section{Results}

Patient, cancer and treatment characteristics

Of 3,517 rectal carcinomas incident in 2004-2008, 2,750 (78\%) had at least one episode of tumour-directed treatment and were included in the analysis. Of these, $88 \%$ of patients had a planned admission, while $12 \%$ were admitted as an emergency (Table 1) and $83 \%$ had surgery. Emergency admission was significantly more common in older patients and in those who were unmarried, smokers, those with one or more co-morbid conditions, public patients and those living in the most deprived areas or living in rural areas. Proximal cancers more often presented as an emergency, as did those in more advanced stages or with unknown grade. Cancers presenting as an emergency had less aggressive treatment and were more likely to be treated in low caseload hospitals.

\section{Statistical models of hazard: direct effects}

At the end of the study period, $29 \%$ of emergency admissions were alive, compared to $46 \%$ of those admitted routinely In multivariate analyses, considering direct effects only, emergency admission increased the hazard by $80 \%$ (HR compared to planned admission 1.80 , $95 \%$ confidence interval (CI) 1.48, 2.19) (Table 2). Other variables which were independently and directly associated with increased hazard were older age, presence of comorbidity, high-grade tumour and more advanced stage; lower hazard was associated with being married, being a private patient, and having cancer sited in the rectum rather than the rectosigmoid junction.

\section{Statistical models of hazard: indirect effects}

Increasing affluence, private patient status and married status indirectly reduced the hazard 
by reducing the rate of emergency admission (Table 3). Private patient status also reduced the hazard through an indirect effect on stage. No other statistically significant indirect effects were seen, and the only significant combined indirect effect (i.e. considering all potential pathways) involved private patient status.

\section{Statistical models of mediating factors}

Table 4 shows the multivariate analysis of factors associated with emergency presentation. Factors associated, in multivariate analyses, with a higher rate of emergency presentation were older age, more advanced stage or higher grade of cancer, cancer site in the rectum and residence in the Western region; those associated with a lower risk were being married, being a private patient, residing in the Southern region and (marginally) residence in a less deprived area. Patients first admitted as an emergency were less likely to receive optimal (or more aggressive) treatment or to have their main treatment in a high caseload hospital.

A higher rate of optimal (or more aggressive) treatment was seen in married patients and those with more advanced disease, while a lower rate was seen in patients living in less deprived areas and those who were admitted as an emergency. Treatment in a high caseload hospital was more frequent in patients from less deprived areas and those with more comorbidity, and less frequent in those living in areas outside the Dublin/Mid-Leinster region or with medium or low population density, and for emergency admissions. Later stage cancers were diagnosed more commonly in patients with high-grade cancers and less frequently amongst older or private patients, or those with one or more comorbid conditions. 


\section{Discussion}

We have used a relatively novel method, based on the principles of structural equation modelling, which can model direct and indirect effects of prognostic factors on the hazard in a sensitive and time-dependent way. This model is fundamentally different from the classical linear regression model or ANOVA, as it includes structured relationships between variables Our primary objective was to assess the direct and indirect impacts of socio-economic inequalities - in particular age, deprivation, marital status and possession of private health insurance — on survival from rectal cancer, and the role of emergency presentation in the observed variation in outcomes.

In this large population-based study, $12 \%$ of first admissions for diagnosis or treatment of rectal cancer were as an emergency. Apart from cancer stage, emergency admission had the strongest direct effect on poor survival, which makes it particularly important to better understand what influences it and how it inter-relates with other factors that may influence survival. In Ireland, although some of the larger private hospitals have emergency rooms, most emergency admissions will be to public hospitals. However patients with private health insurance who present in this way will be recorded as private patients by the public hospital, so we do not consider that having health insurance, or being a private patient, introduces any bias in the designation of patients as public or private.

We succeeded in estimating and testing a number of indirect effects and showed that emergency admission mediates a significant part of the influence of deprivation, private health insurance and marital status on survival. Emergency presentations pose complex clinical challenges ${ }^{11,12}$, and are associated with advanced stage and co-morbidity ${ }^{4,13-15}$ and a high rate of post-operative complications ${ }^{14}$. Some of the adverse impact of emergency admission may be mitigated by admission to a specialist centre which can deal with these 
complexities, and there may be a case for transfer to a specialist centre for definitive surgery. Affluence and health insurance had direct effects on survival, independent of any of the other prognostic factors studied. This may be due to residual confounding ${ }^{4}$ due to undetected comorbidity — for instance, the prevalence of smoking and obesity is higher in more deprived populations in Ireland ${ }^{16}$. Although our analysis adjusted for comorbidity, this probably does not capture more subtle levels of general unfitness or lifestyle behaviours that are associated with poor survival. As the patients who were never admitted to public hospitals were assigned a co-morbidity score of 0 , co-morbidity was not fully adjusted for in these patients, which would result in a slight under-estimation of the positive effect of health insurance on survival.

Emergency admission of rectal cancer carries a much higher mortality than planned admission regardless of cancer stage at presentation ${ }^{4,14,17}$. It is not possible to estimate directly from our data, how many emergency admissions would be "preventable" but as under $6 \%$ of private patients in the most affluent areas had emergency admission compared to $20 \%$ of public patients in the most deprived areas, a significant number of emergency admissions seems avoidable. The factors contributing to emergency admission in this study are similar to those associated with diagnostic and treatment delay ${ }^{1,15,18-20}$. Almost all emergency admissions are likely to have been preceded by symptoms, although in a minority of cases the disease may have been occult prior to presentation ${ }^{21}$. Any delay, whether due to patient or health system factors ${ }^{22-26}$, will make progression and emergency admission more likely.

Patients may delay acting on symptoms for reasons which are cultural, attitudinal, financial, social or geographical ${ }^{3,18,27-29}$. Delay and emergency admission may be reduced by programmes of education and information on symptoms. Our finding that emergency admission was more frequent in deprived populations and those living alone points to the 
importance of social support and easy access to health advice.

The commonest causes of health system delay are late or inappropriate referral by general practitioners and delays in access to investigation (e.g. endoscopy). Although median delays are short relative to the natural history of the disease, patients with very long delays are likely to eventually present as emergencies, with a significant impact on survival. General practitioners have been shown, in a number of countries, to delay before referring patients with symptoms of bowel cancer for investigation, despite the risks of obstruction, perforation or haemorrhage ${ }^{4,13,14,30}$. These symptoms (even those which are alarming, such as rectal bleeding) have a low positive predictive value ${ }^{31-34}$ and patients with vague or non-specific symptoms may experience long delays, potentially ending in emergency admission. As private patients in Ireland have a lower GP consultation rate than average, a higher level of use of GP care does not seem to have a major effect on diagnostic delay ${ }^{16}$. It has been suggested that the GP's "gatekeeper" role results in fewer and later referrals of patients with suspect symptoms ${ }^{35,36}$, and it is reasonable to assume that private health insurance reduces emergency presentation by allowing rapid access by GPs to specialist assessment and endoscopy. Waiting times for endoscopy in Ireland are much shorter for private patients. At the end of 2014,4850 public patients ( $37 \%$ of those on the waiting list) had been waiting for more than 13 weeks for GI endoscopy ${ }^{37}$, while waiting times for private endoscopy, urgent or routine, are of the order of a week ${ }^{38}$. Public patients with non-threatening symptoms are therefore at higher risk of emergency admission than private patients, who can opt to bypass queues for secondary care ${ }^{39}$. However, although emergency admission would be less frequent if doctors referred earlier and more often ${ }^{20}$ investigation of suspected colorectal cancer is expensive ${ }^{40}$ and there must be a balance between over-and under-referral. The consequence of more open access may be fewer emergency admissions but higher costs for investigation of the many symptomatic patients who turn out not to have cancer ${ }^{41}$. 


\section{References}

1. Abel GA, Shelton J, Johnson S, Elliss-Brookes L, Lyratzopoulos G. Cancer-specific variation in emergency presentation by sex, age and deprivation across 27 common and rarer cancers. Br J Cancer 2015;112 Suppl 1:S129-36.

2. Downing A, Aravani A, Macleod U, Oliver S, Finan PJ, Thomas JD, Quirke P, Wilkinson JR, Morris EJA. Early mortality from colorectal cancer in England: a retrospective observational study of the factors associated with death in the first year after diagnosis. Br J Cancer 2013;108:681-5.

3. Zhang J, Fang L, Wu X, Liu J, Zhang C, Dai D. Factors associated with delaying medical assessment of patients and impacting the prognosis of rectal cancer. $2015 \mathrm{Feb}$ 24. Eur J Cancer Prev 2015;Epub.

4. McPhail S, Elliss-Brookes L, Shelton J, Ives A, Greenslade M, Vernon S, Morris EJA, Richards M. Emergency presentation of cancer and short-term mortality. Br J Cancer 2013;109:2027-34.

5. O'Brien K, Comber H, Sharp L. Completeness of case ascertainment at the Irish National Cancer Registry. Ir J Med Sci 2013;

6. Haase T, Pratschke J. The Pobal HP Deprivation Index. Dublin, Ireland: Haase and Pratschke, 2012.

7. Central Statistics Office. Census 2006 Volume 2 - Age and Marital Status [Internet]. Dublin, Ireland: Stationery Office, Dublin, 2007. Available from:

http://www.cso.ie/en/census/census2006reports/census2006volume2ageandmaritalstatus/

8. NCCN Clinical Practice Guidelines in Oncology: rectal cancer [Internet]. [cited 2015 Aug 24];Available from:

http://www.nccn.org/professionals/physician_gls/f_guidelines.asp\#site

9. Muthen B, Masyn K. Discrete-Time Survival Mixture Analysis. J Educ Behav Stat 2005;30:27-58.

10. Muthén L, Muthén B. MPlus User's Guide. 5th ed. Los Angeles, CA: Muthén \& Muthén, 2007.

11. Lewis MA, Hendrickson AW, Moynihan TJ. Oncologic emergencies: Pathophysiology, presentation, diagnosis, and treatment. CA Cancer J Clin 2011;61:287-314.

12. Mitchell AD, Inglis KM, Murdoch JM, Porter GA. Emergency Room Presentation of Colorectal Cancer: A Consecutive Cohort Study. Ann Surg Oncol 2007;14:1099-104.

13. Thompson MR, Asiimwe A, Flashman K, Tsavellas G. Is earlier referral and investigation of bowel cancer patients presenting with rectal bleeding associated with better survival? Colorectal Dis Off J Assoc Coloproctology G B Irel 2011;13:1242-8. 
14. Coco C, Verbo A, Manno A, Mattana C, Covino M, Pedretti G, Petito L, Rizzo G, Picciocchi A. Impact of emergency surgery in the outcome of rectal and left colon carcinoma. World J Surg 2005;29:1458-64.

15. Hogan J, Samaha G, Burke J, Chang KH, Condon E, Waldron D, Coffey JC. Emergency presenting colon cancer is an independent predictor of adverse disease-free survival. Int Surg 2015;100:77-86.

16. Ipsos MRBI. Healthy Ireland Survey. Stationery Office, Dublin, 2015.

17. Iversen LH. Aspects of survival from colorectal cancer in Denmark. Dan Med J 2012;59.

18. Forbes LJL, Warburton F, Richards MA, Ramirez AJ. Risk factors for delay in symptomatic presentation: a survey of cancer patients. Br J Cancer 2014;111:581-8.

19. Gunnarsson H, Ekholm A, Olsson LI. Emergency presentation and socioeconomic status in colon cancer. Eur J Surg Oncol 2013;39:831-6.

20. Hamilton W. Emergency admissions of cancer as a marker of diagnostic delay. $\mathrm{Br} J$ Cancer 2012;107:1205-6.

21. Lyratzopoulos G, Saunders CL, Abel GA. Are emergency diagnoses of cancer avoidable? A proposed taxonomy to motivate study design and support service improvement. Future Oncol Lond Engl 2014;10:1329-33.

22. Korsgaard M, Pedersen L, Sørensen HT, Laurberg S. Reported symptoms, diagnostic delay and stage of colorectal cancer: a population-based study in Denmark. Colorectal Dis 2006;8:688-95.

23. Barrett J, Jiwa M, Rose P, Hamilton W. Pathways to the diagnosis of colorectal cancer: an observational study in three UK cities. Fam Pract 2006;23:15-9.

24. Biswas M, Ades AE, Hamilton W. Symptom lead times in lung and colorectal cancers: what are the benefits of symptom-based approaches to early diagnosis? $\mathrm{Br} J$ Cancer 2015;112:271-7.

25. Hamilton W, Coleman MG, Rubin G. Colorectal cancer. BMJ 2013;346:f3172.

26. Cleary J, Peters TJ, Sharp D, Hamilton W. Clinical features of colorectal cancer before emergency presentation: a population-based case-control study. Fam Pract 2007;24:36.

27. Korsgaard M, Pedersen L, Sørensen HT, Laurberg S. Reported symptoms, diagnostic delay and stage of colorectal cancer: a population-based study in Denmark. Colorectal Dis 2006;8:688-95.

28. Macleod U, Mitchell ED, Burgess C, Macdonald S, Ramirez AJ. Risk factors for delayed presentation and referral of symptomatic cancer: evidence for common cancers. Br J Cancer 2009;101:S92-101.

29. Tomlinson C, Wong C, Au H-J, Schiller D. Factors associated with delays to medical 
assessment and diagnosis for patients with colorectal cancer. Can Fam Physician Med Fam Can 2012;58.

30. Majumdar SR, Fletcher RH, Evans AT. How does colorectal cancer present? Symptoms, duration, and clues to location. Am J Gastroenterol 1999;94:3039-45.

31. Fijten GH, Blijham GH, Knottnerus JA. Occurrence and clinical significance of overt blood loss per rectum in the general population and in medical practice. Br J Gen Pract J R Coll Gen Pract 1994;44:320-5.

32. Fijten GH, Starmans R, Muris JW, Schouten HJ, Blijham GH, Knottnerus JA. Predictive value of signs and symptoms for colorectal cancer in patients with rectal bleeding in general practice. Fam Pract 1995;12:279-86.

33. Thompson null, Pond null, Ellis null, Beach null, Thompson null. Rectal bleeding in general and hospital practice; "the tip of the iceberg." Colorectal Dis Off J Assoc Coloproctology G B Irel 2000;2:288-93.

34. Hamilton W, Round A, Sharp D, Peters TJ. Clinical features of colorectal cancer before diagnosis: a population-based case-control study. Br J Cancer 2005;93:399-405.

35. Rose PW, Rubin G, Perera-Salazar R, Almberg SS, Barisic A, Dawes M, Grunfeld E, Hart N, Neal RD, Pirotta M, Sisler J, Konrad G, et al. Explaining variation in cancer survival between 11 jurisdictions in the International Cancer Benchmarking Partnership: a primary care vignette survey. BMJ Open 2015;5:e007212.

36. Vedsted P, Olesen F. Are the serious problems in cancer survival partly rooted in gatekeeper principles? An ecologic study. Br J Gen Pract J R Coll Gen Pract 2011;61:e508-12.

37. Health Service Executive. Health Service Performance Assurance Report [Internet]. 2014; Available from: http://www.hse.ie/eng/services/publications/corporate/performancereports/d14par.pdf

38. Irish Health. All hail the mighty waiting list [Internet]. 2011;Available from: http://www.irishhealth.com/article.html?id=18986

39. Lynch BM, Baade P, Fritschi L, Leggett B, Owen N, Pakenham K, Newman B, Aitken JF. Modes of presentation and pathways to diagnosis of colorectal cancer in Queensland. Med J Aust 2007;186:288-91.

40. Bending MW, Trueman P, Lowson KV, Pilgrim H, Tappenden P, Chilcott J, Tappenden $\mathrm{J}$, Aalto P. Estimating the direct costs of bowel cancer services provided by the National Health Service in England. Int J Technol Assess Health Care 2010;26:362-9.

41. Thompson MR, Heath I, Ellis BG, Swarbrick ET, Wood LF, Atkin WS. Identifying and managing patients at low risk of bowel cancer in general practice. BMJ 2003;327:263-5. 
Acknowledgements

This research was supported by grant HIC12COM from the Irish Cancer Society 
Table 1. Patient, cancer and treatment characteristics by admission type

year of incidence

planned $(\mathrm{N}=2708) \quad$ emergency $(\mathrm{N}=342)$

Total chisquare

2004
2005
2006
2007
2008

vital status at end of followup

alive

dead

age at diagnosis

$$
\begin{array}{r}
<60 \\
60-69 \\
70-79 \\
80+
\end{array}
$$

$\operatorname{sex}$

$\begin{array}{ll}453 & (86 \%) \\ 459 & (86 \%) \\ 453 & (86 \%) \\ 537 & (90 \%) \\ 506 & (89 \%)\end{array}$

$\begin{array}{ll}73 & (14 \%) \\ 72 & (14 \%) \\ 74 & (14 \%) \\ 61 & (10 \%) \\ 62 & (11 \%)\end{array}$

526

0.146

531

527

598

$506 \quad(89 \%)$

$100 \quad(7 \%)$

$\begin{array}{ll}1304 & (93 \%) \\ 1104 & (82 \%)\end{array}$

242

(18\%)

$702 \quad(92 \%)$

$63 \quad(8 \%)$

$86 \quad(11 \%)$

$697 \quad(89 \%)$

112

$(11 \%)$
$(14 \%)$

$81 \quad(21 \%)$

568

$703 \quad(86 \%)$

male

female

$1,578 \quad(88 \%)$

$210 \quad(12 \%)$

$830 \quad(86 \%)$

132 (14\%)

1404

1346

0.001

marital status

married

unmarried

smoking status

$1,536 \quad(90 \%)$

$173 \quad(10 \%)$

$169 \quad(16 \%)$

765

$<0.001$

783

815

387

$872 \quad(84 \%)$

$89 \quad(17 \%)$

$149 \quad(14 \%)$

$55 \quad(9 \%)$

1,788

962

0.134

$433 \quad(83 \%)$

$933 \quad(86 \%)$

1,709

$<0.001$

1,041

$536 \quad(91 \%)$

49

(9\%)

522

$<0.001$

payment status

unknown

private patient

public patient unknown

area deprivation quintile

1 (least deprived)

$\begin{aligned} 876 & (93 \%) \\ 1,447 & (84 \%) \\ 85 & (92 \%)\end{aligned}$

$66 \quad(7 \%)$

$269 \quad(16 \%)$

(8\%)

1,082

591

555

$942<0.001$

1,716

92

$463 \quad(90 \%)$

$52 \quad(10 \%)$

515

$<0.001$

$504 \quad(89 \%)$

$65 \quad(11 \%)$

569

$496 \quad(90 \%)$

$57 \quad(10 \%)$

553

$475 \quad(88 \%)$

$62 \quad(12 \%)$

537

5 (most deprived)

region of residence

$465 \quad(82 \%)$

$103 \quad(18 \%)$

568

$644 \quad(88 \%)$

$84 \quad(12 \%)$

728

$<0.001$

Dublin/North-east

$457 \quad(89 \%)$

$59 \quad(11 \%)$

516

810

$739 \quad(91 \%)$

(9\%)

684

urban/rural residence

West

$558 \quad 82 \%)$

$126 \quad(18 \%)$

949

591

969

cancer site

intermediate-urban

$843 \quad(89 \%)$

$106 \quad(11 \%)$

(10\%)

$144 \quad(15 \%)$

631

2,119

stage at diagnosis

rectosigmoid

$528 \quad(84 \%)$

$103 \quad(16 \%)$

$239 \quad(11 \%)$

0.001

$1,880 \quad(89 \%)$

$25 \quad(6 \%)$

415

$<0.001$

Stage I

$390 \quad(94 \%)$

100

$(15 \%)$

689

$953 \quad(89 \%)$

$115 \quad(11 \%)$

1,068

Stage III

467 (82\%)

$100 \quad(18 \%)$

567 


\begin{tabular}{|c|c|c|c|c|c|c|}
\hline unknown & 9 & $(82 \%)$ & 2 & $(18 \%)$ & 11 & \\
\hline low/intermediate & 1,872 & $(89 \%)$ & 238 & $(11 \%)$ & 2,110 & 0.002 \\
\hline high & 249 & $(86 \%)$ & 42 & $(14 \%)$ & 291 & \\
\hline unknown & 287 & $(82 \%)$ & 62 & $(18 \%)$ & 349 & \\
\hline \multicolumn{7}{|l|}{ Charlson comorbidity score } \\
\hline 0 & 1,666 & $(88 \%)$ & 229 & $(12 \%)$ & 1,895 & 0.001 \\
\hline 1 & 297 & $(82 \%)$ & 66 & $(18 \%)$ & 363 & \\
\hline 2 & 170 & $(81 \%)$ & 39 & $(19 \%)$ & 209 & \\
\hline unknown & 275 & $(97 \%)$ & 8 & $(3 \%)$ & 283 & \\
\hline \multicolumn{7}{|l|}{ treatment intensity } \\
\hline less aggressive & 968 & $(84 \%)$ & 182 & $(16 \%)$ & 1,150 & $<0.001$ \\
\hline optimal & 1,259 & $(89 \%)$ & 153 & $(11 \%)$ & 1,412 & \\
\hline more aggressive & 181 & $(96 \%)$ & 7 & $(4 \%)$ & 188 & \\
\hline \multicolumn{7}{|l|}{ caseload of main hospital } \\
\hline 1 (lowest caseload quintile) & 534 & $88 \%)$ & 70 & $(12 \%)$ & 604 & $<0.001$ \\
\hline 2 & 434 & $84 \%)$ & 85 & $(16 \%)$ & 519 & \\
\hline 3 & 445 & $83 \%)$ & 88 & $(17 \%)$ & 533 & \\
\hline 4 & 461 & $93 \%)$ & 35 & $(7 \%)$ & 496 & \\
\hline 5 (highest caseload quintile) & 499 & $93 \%)$ & 39 & $(7 \%)$ & 538 & \\
\hline unknown & 35 & $58 \%)$ & 25 & $(42 \%)$ & 60 & \\
\hline
\end{tabular}


Table 2. Direct effects of patient, cancer and treatment characteristics on hazard ratio

\begin{tabular}{|c|c|c|}
\hline Variable & Value & Hazard ratio (95\% confidence intervals) \\
\hline \multicolumn{3}{|l|}{ emergency admission } \\
\hline & no & 1.00 \\
\hline & yes & $1.80(1.48,2.19)$ \\
\hline \multicolumn{3}{|l|}{ sex } \\
\hline & female & 1.00 \\
\hline & male & $1.26(0.53,2.98)$ \\
\hline \multicolumn{3}{|l|}{ age } \\
\hline & per 10 year increase & $1.38(1.25,1.52)$ \\
\hline \multicolumn{3}{|c|}{ age and sex interaction } \\
\hline & other & 1.00 \\
\hline & male aged $70+$ & $0.98(0.85,1.12)$ \\
\hline \multicolumn{2}{|l|}{ deprivation score } & $067(020116$ \\
\hline \multicolumn{3}{|l|}{ marital status } \\
\hline & never married & 1.00 \\
\hline & married & $0.85(0.74,0.98)$ \\
\hline \multicolumn{3}{|l|}{ private patient } \\
\hline & no & 1.00 \\
\hline & yes & $0.72(0.61,0.84)$ \\
\hline \multicolumn{3}{|l|}{ HSE area } \\
\hline & Dublin Mid-Leinster & 1.00 \\
\hline & Dublin North-east & $1.09(0.88,1.36)$ \\
\hline & South & $1.05(0.88,1.25)$ \\
\hline & West & $1.05(0.86,1.28)$ \\
\hline \multicolumn{3}{|l|}{ urban/rural residence } \\
\hline & high & 1.00 \\
\hline & medium & $1.14(0.95,1.36)$ \\
\hline & low & $1.00(0.84,1.19)$ \\
\hline & unknown & $1.03(0.80,1.33)$ \\
\hline \multicolumn{3}{|l|}{ tumour grade } \\
\hline & low/intermediate & 1.00 \\
\hline & high & $1.77(1.45,2.15)$ \\
\hline \multicolumn{3}{|l|}{ stage } \\
\hline & $\mathrm{I} / \mathrm{II}$ & 1.00 \\
\hline & III/IV & $2.86(2.59,3.15)$ \\
\hline \multicolumn{3}{|l|}{ comorbidities } \\
\hline & no & 1.00 \\
\hline & yes & $1.42(1.21,1.66)$ \\
\hline \multicolumn{3}{|c|}{ optimal treatment regime } \\
\hline & no & 1.00 \\
\hline & yes & $0.90(0.77,1.06)$ \\
\hline \multicolumn{3}{|l|}{ hospital caseload } \\
\hline & 0-200 cases/year & 1.00 \\
\hline & $>200$ cases/year & $0.90(0.78,1.03)$ \\
\hline \multicolumn{3}{|l|}{ site } \\
\hline & rectosigmoid & 1.00 \\
\hline & rectum & $0.84(0.72,0.99)$ \\
\hline year of diagnosis & & $0.92(0.89,0.96)$ \\
\hline
\end{tabular}

Note: Values in bold denote statistically significant values 
Table 3. Indirect effects of affluence, private patient status and marital status on hazard, mediated through cancer and treatment characteristics; coefficients and $95 \%$ confidence intervals

\section{Mediated through:}

optimal treatment

high caseload hospital

late stage

emergency admission

caseload $\rightarrow$ treatment

late stage $\rightarrow$ optimal treatment

late stage $\rightarrow$ high caseload hospital

late stage $\rightarrow$ emergency admission

emergency admission optimal treatment

emergency admission $\rightarrow$ high caseload hospital

late stage $\rightarrow$ high caseload hospital $\rightarrow$ optimal treatment

late stage $\rightarrow$ emergency admission $\rightarrow$ optimal treatment

late stage $\rightarrow$ emergency admission $\rightarrow$ high caseload hospital

late stage $\rightarrow$ emergency admission $\rightarrow$ high caseload hospital $\rightarrow$ optimal treatment

All indirect effects

Direct effect

Total effect

Note: Values in bold denote statistically significant values
Effect of

$0.00(0.00,0.00)$

$0.00(0.00,0.00)$

$-0.12(-0.41,0.18)$

$-0.40(-0.94,0.15)$

$-0.51(-1.11,0.08)$ private patient $0.00(0.00,0.01)$

$0.00(-0.01,0.00)$

$-0.14(-0.22,-0.05)$

$\mathbf{- 0 . 0 4}(-\mathbf{0 . 0 5},-\mathbf{- 0 . 0 2})$

$0.00(0.00,0.00)$

$0.01(-0.01,0.04)$

$0.00(0.00,0.00)$

$0.00(0.00,0.00)$

$0.00(0.00,0.00)$

$0.00(0.00,0.00)$

$0.00(0.00,0.00)$

$0.00(0.00,0.00)$

$0.00(0.00,0.00)$

$0.00(0.00,0.00)$

never married

$-0.01(-0.01,0.00)$

$0.00(0.00,0.00)$

$0.03(-0.05,0.11)$

$\mathbf{- 0 . 0 2}(\mathbf{- 0 . 0 4}, \mathbf{0 . 0 0})$

$0.00(0.00,0.00)$

$0.00(-0.01,0.01)$

$0.00(0.00,0.00)$

$0.00(0.00,0.00)$

$0.00(0.00,0.00)$

$0.00(0.00,0.00)$

$0.00(0.00,0.00)$

$0.00(0.00,0.00)$

$0.00(0.00,0.00)$

$0.00(0.00,0.00)$

$0.00(-0.08,0.08)$

$\mathbf{- 0 . 3 3}(-\mathbf{- 0 . 4 8 , - 0 . 1 7 )} \quad \mathbf{- 0 . 1 6}(-\mathbf{0 . 3 0}, \mathbf{- 0 . 0 2})$

$\mathbf{- 0 . 4 9}(-\mathbf{0 . 6 6}, \mathbf{- 0 . 3 2}) \quad-0.16(-0.31,0.00)$ 
Table 4. Regression coefficients (95\% confidence intervals) of optimum treatment, caseload, tumour stage and first hospital admission type on explanatory variables

\begin{tabular}{|c|c|c|c|c|c|}
\hline variable & values & emergency admission & $\begin{array}{c}\text { optimum or more } \\
\text { aggressive treatment }\end{array}$ & $\begin{array}{c}\text { main treatment in high } \\
\text { caseload hospital }\end{array}$ & late stage \\
\hline year of diagnosis (per year) & & $-0.01(-0.01,-0.01)$ & $0.00(-0.02,0.02)$ & & $0.00(-0.02,0.02)$ \\
\hline \multirow[t]{2}{*}{ sex } & female & & & & \\
\hline & male & $-0.01(-0.15,0.13)$ & $-0.04(-0.24,0.16)$ & $0.03(-0.17,0.23)$ & $0.27(-0.14,0.68)$ \\
\hline age & per 10 year increase & $0.02(0.00,0.04)$ & $-0.10(-0.12,-0.08)$ & $-0.02(-0.04,0.00)$ & $-0.05(-0.09,-0.01)$ \\
\hline \multirow[t]{2}{*}{ age and sex } & other & 0.00 & 0.00 & 0.00 & 0.00 \\
\hline & male aged $70+$ & $0.00(-0.02,0.02)$ & $0.01(-0.03,0.05)$ & $0.00(-0.04,0.04)$ & $-0.03(-0.09,0.03)$ \\
\hline deprivation score & per unit score & $-0.12(-0.24,0.00)$ & $-0.21(-0.35,-0.07)$ & $0.40(0.26,0.54)$ & $-0.02(-0.31,0.27)$ \\
\hline \multirow[t]{2}{*}{ marital status } & never married & 0.00 & 0.00 & 0.00 & 0.00 \\
\hline & married & $-0.04(-0.06,-0.02)$ & $0.05(0.01,0.09)$ & $-0.01(-0.05,0.03)$ & $0.03(-0.05,0.11)$ \\
\hline \multirow{2}{*}{ private patient } & no & 0.00 & 0.00 & 0.00 & 0.00 \\
\hline & yes & $-0.06(-0.08,-0.04)$ & $-0.03(-0.07,0.01)$ & $0.02(-0.02,0.06)$ & $-0.13(-0.21,-0.05)$ \\
\hline \multirow[t]{4}{*}{ HSE area } & Dublin Mid-Leinster & 0.00 & 0.00 & 0.00 & 0.00 \\
\hline & Dublin North-east & $-0.01(-0.05,0.03)$ & $0.01(-0.05,0.07)$ & $-0.14(-0.20,-0.08)$ & $-0.11(-0.23,0.01)$ \\
\hline & South & $-0.04(-0.08,0.00)$ & $-0.05(-0.11,0.01)$ & $-0.13(-0.19,-0.07)$ & $0.04(-0.06,0.14)$ \\
\hline & West & $0.05(0.01,0.09)$ & $0.01(-0.05,0.07)$ & $-0.22(-0.28,-0.16)$ & $0.09(-0.03,0.21)$ \\
\hline \multirow[t]{4}{*}{ urban/rural residence } & high (urban) & 0.00 & 0.00 & 0.00 & 0.00 \\
\hline & medium & $-0.01(-0.05,0.03)$ & $0.01(-0.05,0.07)$ & $-0.23(-0.29,-0.17)$ & $0.02(-0.08,0.12)$ \\
\hline & low (rural) & $0.02(-0.02,0.06)$ & $0.02(-0.04,0.08)$ & $-0.31(-0.35,-0.27)$ & $-0.04(-0.14,0.06)$ \\
\hline & unknown & $0.02(-0.02,0.06)$ & $0.02(-0.06,0.10)$ & $-0.29(-0.37,-0.21)$ & $0.00(-0.14,0.14)$ \\
\hline \multirow[t]{2}{*}{ site } & rectosigmoid & 0.00 & 0.00 & 0.00 & 0.00 \\
\hline & rectum & $0.05(0.01,0.09)$ & $-0.22(-0.26,-0.18)$ & $-0.10(-0.14,-0.06)$ & $0.06(-0.02,0.14)$ \\
\hline \multirow[t]{2}{*}{ tumour grade } & low/intermediate & 0.00 & 0.00 & 0.00 & 0.00 \\
\hline & high & $0.02(-0.02,0.06)$ & $-0.01(-0.07,0.05)$ & $0.03(-0.03,0.09)$ & $0.47(0.37,0.57)$ \\
\hline \multirow[t]{2}{*}{ stage } & I/II & 0.00 & 0.00 & 0.00 & \\
\hline & III/IV & $0.03(0.01,0.05)$ & $0.03(0.01,0.05)$ & $0.01(-0.01,0.03)$ & \\
\hline \multirow[t]{2}{*}{ comorbidities } & no & 0.00 & 0.00 & 0.00 & 0.00 \\
\hline & yes & $0.06(0.02,0.10)$ & $0.01(-0.03,0.05)$ & $0.06(0.02,0.10)$ & $-0.10(-0.20,0.00)$ \\
\hline \multirow[t]{2}{*}{ first admission } & booked & & 0.00 & 0.00 & \\
\hline & emergency & & $-0.09(-0.15,-0.03)$ & $-0.03(-0.09,0.03)$ & \\
\hline \multirow[t]{2}{*}{ hospital caseload } & $0-100$ cases/year & & 0.00 & & \\
\hline & $>100$ cases/year & & $0.02(-0.02,0.06)$ & & \\
\hline
\end{tabular}

